\title{
Estimating Specific Features of the Optical Property Variability in the Black Sea Waters Using the Data of SeaWiFS and MODIS Satellite Instruments
}

\author{
V. S. Suetin, S. N. Korolev* \\ Marine Hydrophysical Institute, Russian Academy of Sciences, Sevastopol, Russian Federation \\ *e-mail: s.korolev@mhi-ras.ru
}

Problem of quantitative interpretation of the Black Sea observations provided by the SeaWiFS and MODIS satellite instruments is considered in the terms of spectral dependencies of the seawater optically active components. For this purpose, the results of standard data (accumulated in the NASA archive) processed by the GIOP (Generalized ocean color inversion model for retrieving marine Inherent Optical Properties) complex method are analyzed. As these results often contain significant distortions related to the atmospheric disturbances, selection of reliable test data implies the following requirement: large cloudless areas of the sea should contain no sudden chaotic spatial-temporal fluctuations of all the defined products and no false local correlations between the fields of the atmospheric and seawater parameters. Besides, imposed are the conditions for sufficiently accurate model reproduction of the empirical spectra of the sea surface reflectance and coincidence of the results obtained from the SeaWiFS and MODIS instruments. Application of the GIOP method permits to analyze the features of variations and the relative role of the light absorption components in the upper water layer associated with phytoplankton and the dissolved yellow substance. In the deepwater part of the Black Sea in summer, yellow substance makes the main contribution to absorption, and during the summer-autumn transition period, approximately equal growth of both the phytoplankton and the yellow substance absorptions is observed. Having been compared, the features of the Black Sea and the Equatorial Pacific waters are represented as an example. In contrast to the Black Sea, phytoplankton in the Equatorial Pacific is a dominating factor, whereas the yellow substance content remains almost unchanged.

Keywords: the Black Sea, the Pacific Ocean, satellite observations, spectral dependencies, optical characteristics, MODIS, SeaWiFS, GIOP, phytoplankton, yellow substance.

Acknowledgements: the authors are grateful to the NASA GSFC processing satellite information group (URL: http://oceancolor.gsfc.nasa.gov/) for the opportunity to use the empirical data. The research was carried out within the framework of the State Order No. 0827-2014-0011 "Investigation of Regularities of the Marine Environment State Changes Based on the Operational Observations and the Nowcast, Forecast and Reanalysis System Data on the Marine Environment State" (Operational oceanography code).

For citation: Suetin, V.S. and Korolev, S.N., 2018. Estimating Specific Features of the Optical Property Variability in the Black Sea Waters Using the Data of SeaWiFS and MODIS Satellite Instruments. Physical Oceanography, [e-journal] 25(4), pp. 330-340. doi:10.22449/1573-160X-20184-330-340

DOI: $10.22449 / 1573-160 X-2018-4-330-340$

(c) 2018, V. S. Suetin, S. N. Korolev

(C) 2018, Physical Oceanography

\section{Introduction}

The information obtained by SeaWiFS, MODIS optical instruments and others operating in space can be used to control and study the various processes of the marine water area state variability. The results of regular global satellite observations and products of their processing are accumulated on an on-going basis in special archives with free access via the Internet. The equipment installed on the 
satellite registers accurately the outgoing radiation of various wavelengths of the visible spectrum range, which in a complex manner depends on a multitude of variable parameters of the atmosphere and the upper sea layer. These include the coefficients of light absorption $a(\lambda)$ and backscattering $b_{\mathrm{b}}(\lambda)$ in water ( $\lambda$ is the wavelength of light), chlorophyll $a$ concentration, optical thickness of the aerosol component of the atmosphere, etc.

One of the directions of using satellite measurements is to determine the numerical values of these parameters. For this purpose, different models, methods and algorithms can be applied. Simplified approaches convenient for carrying out mass calculations are most often used. In these, in an explicit or implicit form, it is assumed that the number of independent factors the results of satellite measurements depend on is substantially limited. Such methods include, for example, those described in [1-5]. Such methods cannot provide high efficiency in interpreting observational data in a wide variety of conditions that vary from region to region, in different seasons and so on.

The complex methods designed for more accurate accounting of all the main effects manifested in variations in the optical properties of seawater [6-8] are also known. In recent years, the NASA operating system for satellite data processing has been supplemented with a procedure implementing one of such complex methods Generalized ocean color inversion model for retrieving marine Inherent Optical Properties (GIOP) [9]. Accordingly, a wider set of parameters including $a(\lambda)$ and $b_{\mathrm{b}}(\lambda)$ also includes the light absorption in the sea due to phytoplankton $a_{\mathrm{ph}}(\lambda)$ and yellow substance $a_{\mathrm{dg}}(\lambda)$ (in combination with detritus) content. NASA archives have added the GIOP application results for the accumulated earlier global observation arrays for the entire operation time period of SeaWiFS and MODIS instruments in space.

GIOP is based on physical models that describe in a parametric form the dependence of the optical properties of the sea on the light wavelength and the content of the main optically active impurities in water. These models are obviously more or less approximate in nature. Therefore, it is required to verify the GIOP operating capacity, taking into account the specific features of the optical properties of the Black Sea water. For this purpose, it is useful to consider in detail some of the most characteristic examples that reflect the specific features of the Black Sea waters. Similar studies were earlier performed in [7, 10] using other methods. Some results of the GIOP application are described in [11], but there a somewhat different problem was considered.

\section{The Black Sea}

The initial data in the calculations of the seawater characteristics by the GIOP method are the spectral values of the sea surface reflectance $R_{\mathrm{rs}}(\lambda)$ for all measurement channels of the visible range, which are obtained at one of the first stages of the satellite observations processing in atmospheric correction. As is known, for the Black Sea the results of $R_{\mathrm{rs}}(\lambda)$ calculation can often contain significant errors. The main origin for them is the difference between the optical properties of a real atmospheric aerosol from those models that are incorporated 
into the NASA-developed data processing system for global satellite observations. In addition, the accuracy of $R_{\mathrm{rs}}(\lambda)$ determination is influenced by factors such as the sun glint, the errors in setting the calibration parameters of the instrument, the increased sensitivity of the sensors to changes in the recorded radiation polarization, etc.

Consequently, to obtain reliable conclusions it is necessary to avoid the use of distorted data and limit to analyzing a relatively small number of examples with the most reliable initial values of $R_{\mathrm{rs}}(\lambda)$. For their selection, the criteria used earlier in [10-13] can be applied. According to these criteria, it is required that within the large cloudless sea areas there are no sharp chaotic spatio-temporal fluctuations of all determined parameters (including atmospheric ones) and false local correlations between the products of calculations of the atmosphere and sea water characteristics. In addition, a sufficiently accurate model reproduction of $R_{\mathrm{rs}}(\lambda)$ empirical spectra and the coincidence of the results obtained from SeaWiFS and MODIS instruments are needed. Below the results of the analysis of test data obtained using these criteria are considered.

Fig. 1 shows charts of the spatial distribution of chlorophyll $a$ concentration (denoted by $C_{a}$ ) on 11.08.2006 and 04.10.2006. Here, the results of $C_{a}$ calculation by the traditional simplified method [1] are used. As is known, in the Black Sea this method can lead to errors, nevertheless, the charts in Fig. 1 indirectly represent the optical properties of water in these days.
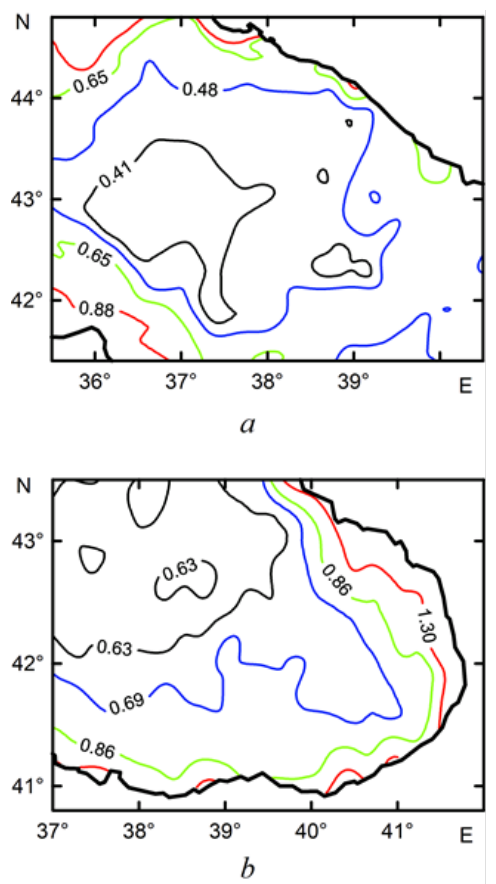

Fig. 1. Charts of spatial distribution of value $C_{a}, \mathrm{mg} \cdot \mathrm{m}^{-3}$ in the eastern Black Sea on 11.08.2006 (a) and 04.10.2006 (b) 
In the deep-water part of the sea on 4.10.2006 within a large area the $C_{a}$ field was almost homogeneous and in the east, as the coast approached, the $C_{a}$ growth took place. It is essential that on this day almost the entire eastern part of the Black Sea was free from cloud cover and provided with results of practically simultaneous surveys by MODIS and SeaWiFS instruments. For the test area considered below, the time difference between the two instruments does not exceed 20 minutes.

Fig. 2 shows the values of the $a(443)$ and $a_{\mathrm{ph}}(443)$ calculated by the GIOP method, selected from the band located about $42,0^{\circ} \mathrm{N}$ and having a width of $0.25^{\circ}$ in latitude. In these graphs, the MODIS data in the Level-3m format obtained on 4.10.2006 were used.

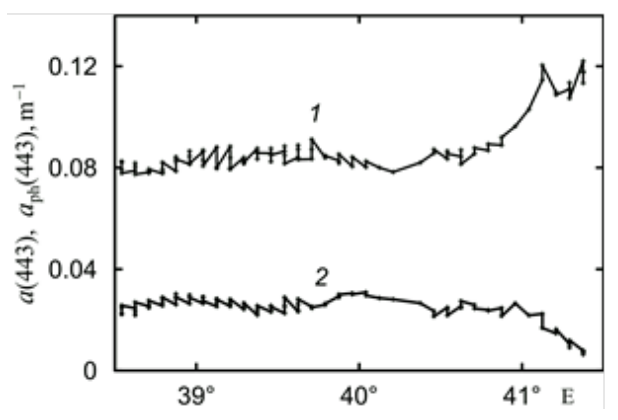

Fig. 2. Variations of the absorption parameters obtained on 04.10.2006 within the narrow strip close to $42.0^{\circ} \mathrm{N}: a(443)$ is curve 1 and $a_{\mathrm{ph}}(443)$ is curve 2

In Fig. 2 on the area to the west from $\sim 41^{\circ} \mathrm{E} a(443)$ and $a_{\mathrm{ph}}(443)$ values do not almost change. But approaching the coast in the east, $a(443)$ increases in a natural way, but the results of the $a_{\mathrm{ph}}(443)$ determination show a significant decrease. The chart in Fig. 1 shows an increase in the chlorophyll $a$ concentration in the same region, and therefore an increase in $a_{\mathrm{ph}}(443)$ should also be expected. It is noteworthy that, there is no such decrease in $a_{\mathrm{ph}}(443)$ in the SeaWiFS data. These contradictions are a clear example of the manifestation of distortions in the GIOP method application results.

Such distortions are often found in the analysis of satellite data processing products using similar to GIOP complex methods, aimed at simultaneous determination of many unknown seawater parameters based on measurements in a complete set of spectral channels of instruments operating in space. This is the general property of such (синонимичные конструкции) problems, consisting in the ambiguity and instability of their solutions with respect to various inaccuracies in the model and in the initial data. A detailed study of this problem is beyond the scope of the present article, some of its aspects are considered in [2, 8, 10, 14].

The Level-3m format data used here and below are the final processing products interpolated to the regular grid nodes, for which all necessary transformation operations are carried out, including automatic rejection of hardly usable samples for a number of formal criteria. The analysis in Fig. 2 and many other similar examples of the Black Sea observations suggests that in the GIOP method implementation such a rejection does not completely exclude the distorted 
data. The aforementioned criteria are more effective. At the same time, despite the fact that MODIS and SeaWiFS instruments often display various serious distortions in the Black Sea observations, it remains possible to obtain useful information by careful selection of observational data in the most favorable situations.

In the example of the eastern Black Sea survey on 4.10.2006, a quite favorable area is located near $39^{\circ} \mathrm{E}$ within the data sampling used in Fig. 2. Fig. 3 and Tab. 1 shows the results of applying the GIOP to MODIS data for one of the grid nodes in this area. Here, the results of the Black Sea survey data processing obtained in the same way on 11.08.2006 are also given.
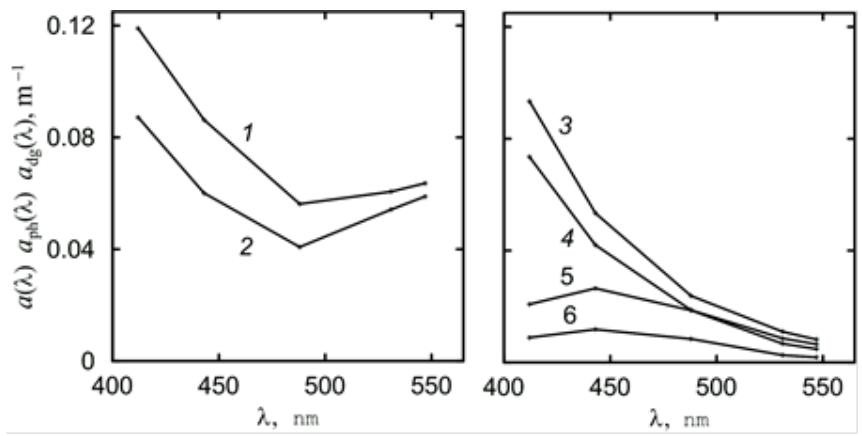

Fig. 3. Results of determining the absorption spectral characteristics by the GIOP method based on the Black Sea surveys performed by the instrument MODIS on 04.10.2006 $(1,3,5)$ and on 11.08.2006 $(2,4,6): 1$ and 2 are $a(\lambda) ; 3$ and 4 are $a_{\mathrm{dg}}(\lambda) ; 5$ and 6 are $a_{\mathrm{ph}}(\lambda)$

T a ble 1

\section{Results of determining the chlorophyll $a$ concentration and the optical parameters of the Black Sea waters using the GIOP method}

\begin{tabular}{|c|c|c|c|c|c|c|}
\hline \multirow{2}{*}{ Date } & \multicolumn{2}{|c|}{ Coordinates } & \multirow{2}{*}{$a_{\mathrm{ph}}(443), \mathrm{m}^{-1}$} & \multirow{2}{*}{$a_{\mathrm{dg}}(443), \mathrm{m}^{-1}$} & \multirow{2}{*}{$C_{a}, \mathrm{mg} \cdot \mathrm{m}^{-3}$} & \multirow{2}{*}{$C_{a g}, \mathrm{mg} \cdot \mathrm{m}^{-3}$} \\
\hline & ${ }^{\circ} \mathrm{N}$ & ${ }^{\circ} \mathrm{E}$ & & & & \\
\hline 11.08.2006 & 42.37 & 37.71 & 0.012 & 0.042 & 0.42 & 0.21 \\
\hline 4.10 .2006 & 42.21 & 39.04 & 0.025 & 0.055 & 0.72 & 0.48 \\
\hline
\end{tabular}

The examples in Fig. 3 and in Tab. 1 satisfy the above criteria, including the condition that the results of calculations of all parameters and products of the GIOP application for the two devices coincide. It is also essential that in this case the models used in GIOP provide accurate reproduction of the empirical spectral dependences of the sea surface reflectance $R_{\mathrm{rs}}(\lambda)$.

These examples are interesting in that they were obtained in the same year in the same sea area and reflect the usual changes in optical properties from summer to autumn. Despite the fact that the data in Fig. 3 and in Tab.1 refer to readings in single nodes of the grid of the Level-3m format, these data characterize the properties of extended areas in the deep-water part of the Black Sea.

The GIOP method application results allow analyzing the features of the variations and the relative role of the components that affect the light absorption in the upper layer of water. In the transition from summer to autumn, approximately the same increase is observed in each of $a_{\mathrm{ph}}(\lambda)$ and $a_{\mathrm{dg}}(\lambda)$ values, but the relative changes 
of $a_{\mathrm{dg}}(\lambda)$ are less pronounced, since this component makes the main contribution to the total absorption. The latter circumstance serves as one of the key sources of errors in the determination of $C_{a}$ in the Black Sea by satellite measurements.

It should be noted that conclusions similar in meaning were formulated earlier in $[7,15-17]$ based on the field data analysis and in $[2,10]$ - in the interpretation of satellite observations. The new results obtained in the present study contain a more detailed analysis of key effects and are of particular interest as they characterize concrete examples of the GIOP method application.

According to [18], in the waters of the open part of the Black Sea, the light absorption by detritus is much less than $a_{\mathrm{ph}}(\lambda)$. So, it can be assumed that the main role is played by the yellow substance, and in the considered situations in the notation of $a_{\mathrm{dg}}(\lambda)$, detritus appears only to follow exactly the notation system adopted in the GIOP method description [9].

In addition to estimating the chlorophyll $a$ concentration, calculated in the traditional simplified way [1], Tab. 1 also demonstrates the results of its calculations by the GIOP method, denoted as $C_{a g}$. Both these values are determined from the data of satellite surveys by the MODIS instrument. It is easy to see that $C_{a}$ exceeds $C_{a g}$ approximately one and a half to two times. This difference is a direct consequence of the specifics of the optical properties of water in the Black Sea. It was previously established that a simplified method [1] often overestimates $C_{a}$ in the Black Sea [2, 19, 20], so the results of calculations by the GIOP method can be considered to be closer to reality.

This is also evidenced by the fact that the application of a specially developed regional algorithm for the Black Sea in [2] based on measurements on 11.08.2006 and 4.10.2006 leads to estimates of the chlorophyll $a$ concentration close to $C_{a g}$ : 0.26 and $0.41 \mathrm{mg} \cdot \mathrm{m}^{-3}$. In addition, the value of $C_{a g}$ obtained for 11.08 .2006 is in full agreement with the usual conditions at this time of year in the deep-water part of the Black Sea. For 4.10.2006, the $C_{a g}$, determined from satellite measurements, and the corresponding $R_{\mathrm{rs}}(\lambda)$, are close to the results of in situ measurements described in [7] carried out on 14.09.2000 at one of the stations during the expedition in the northeastern part of the sea.

\section{The Pacific Ocean}

For clearer understanding the GIOP method possibilities and evaluation the features of the optical properties of the Black Sea water, it is useful to compare them with the properties of waters of other areas. To this end, Tab. 2 and Fig. 4 gives examples of SeaWiFS data processing products specially selected from surveys of the equatorial region of the Pacific Ocean carried out on 29.05.2003 and 13.06.2010. Here, as well as for the Black Sea, the GIOP method application results, presented in the Level-3m format, are used. Under negative values of the northern latitude, the corresponding values of southern latitude are meant in Tab. 2. 
Table 2

Results of determining the Pacific Ocean water optical parameters using the GIOP method

\begin{tabular}{c|c|c|c|c|c}
\hline \multirow{2}{*}{ Date } & \multicolumn{2}{|c|}{ Coordinates } & \multirow{2}{*}{$a_{\mathrm{ph}}(443), \mathrm{m}^{-1}$} & $a_{\mathrm{dg}}(443), \mathrm{m}^{-1}$ & $C_{a}, \mathrm{mg} \cdot \mathrm{m}^{-3}$ \\
\cline { 2 - 5 } & \multicolumn{1}{c}{$\mathrm{N}$} & ${ }^{\circ} \mathrm{W}$ & 0.046 & 0.013 & 0.62 \\
\hline 13.06 .2010 & 0.79 & 135.54 & 0.015 & 0.010 & 0.18 \\
29.05 .2003 & 2.46 & 135.54 & 0.013 & 0.010 & 0.16 \\
& -1.71 & 115.29 & 0.025 & 0.012 & 0.29 \\
& -0.71 & 115.29 & 0.035 & 0.013 & 0.45 \\
& 0.87 & 115.29 & 0.059 & 0.010 & 0.84 \\
\hline
\end{tabular}
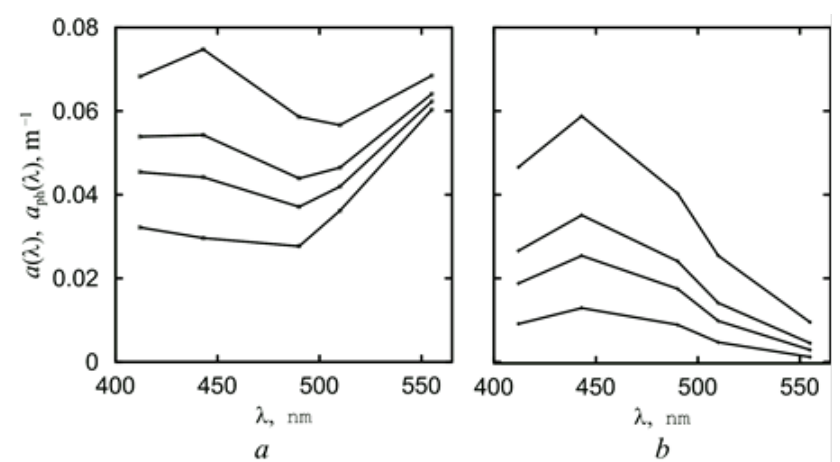

Fig. 4. Results of determining spectral dependencies of the values $a(\lambda)-(a)$ and $a_{\mathrm{ph}}(\lambda)-(b)$ based on the Pacific Ocean surveys performed by the SeaWiFS instrument on 29.05.2003

In the considered Pacific Ocean area, there is an interesting phenomenon associated with the El Niño-South Oscillation, accompanied by an occasional increase in the chlorophyll $a$ content and a decrease in the water transparency in a narrow band near the equator [21, 22]. Fig. 5 schematically shows the compositeonal chart of the spatial distribution of the chlorophyll $a$ concentration in the equatorial Pacific Ocean relating to the period from May 25 to June 1, 2003, constructed from the results of satellite measurement processing by the traditional method contained in the NASA archive [1].

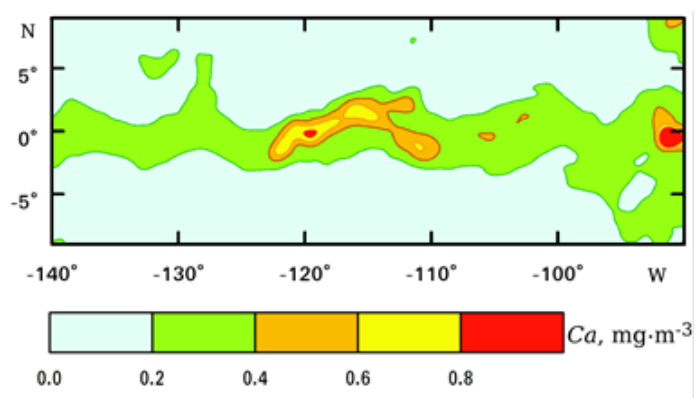

Fig. 5. Compositional chart of $C_{a}$ distribution in the equatorial Pacific Ocean based on the satellite measurements obtained from May 25, 2003 to June 1, 2003 
By the levels of the light absorption coefficient and $C_{a}$, the examples in Tab. 2 and in Fig. 4, are well correlated with those discussed above for the Black Sea. Their comparison indicates a significant difference in the laws governing the formation of optical properties of water in the Black Sea and the Pacific Ocean. The main difference is that the values of $a_{\mathrm{dg}}(443)$ from Tab. 2 have a relatively low level and almost do not change, and the corresponding variations of $a(443)$ are almost entirely conditioned by $a_{\mathrm{ph}}(443)$ variations. At that, the spectra $a(\lambda)$ in the Black Sea and in the ocean are of different shapes (абсолютно нормальное использование).

In a graphic form, the relation between $a_{\mathrm{ph}}(443)$ and $a_{\mathrm{dg}}(443)$ values in the considered Black Sea and in the Pacific Ocean areas are shown in Fig. 6. Here, in addition to the new data described above, the $a_{\mathrm{ph}}(443)$ and $a_{\mathrm{dg}}(443)$ determination results, presented in $[10,11]$, are plotted. In [11], $a_{\mathrm{ph}}(443)$ and $a_{\mathrm{dg}}(443)$ values from the NASA archive (obtained by GIOP) were used, and in [10] they were calculated by a somewhat similar method. At that, for one point, the results of $R_{\mathrm{rs}}(\lambda)$ measurements dated 14.09.2000 at the aforementioned station during the expedition in the northeastern Black Sea carried out by spectroradiometer floating on the water surface, were taken as initial data [7]. For the other four points, the $R_{\mathrm{rs}}(\lambda)$ spectra, determined according to SeaWiFS data, were used in the calculations.

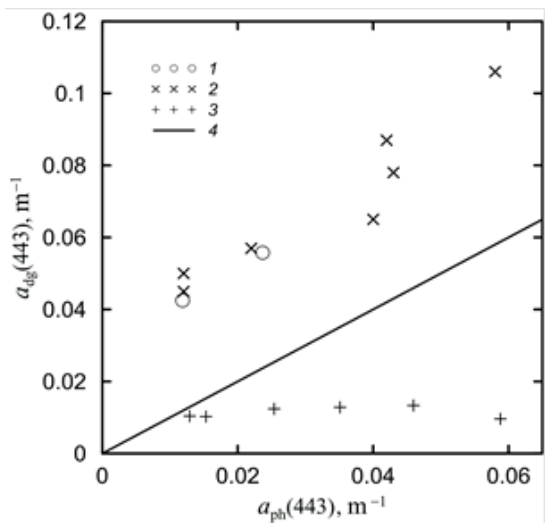

Fig. 6. Correlation between the values $a_{\mathrm{ph}}(443)$ and $a_{\mathrm{dg}}(443): 1$ is the Black Sea on 11.08 .2006 and on 4.10.2006; 2 is the Black Sea based on the data from [ 10, p. 82; 11, p. 59]; 3 is the Pacific Ocean on 29.05.2003 and on 13.06.2010; 4 is the straight line $a_{\mathrm{dg}}(443)=a_{\mathrm{ph}}(443)$

In Fig. 6, there are uniform, but significantly different, trends in each of the two groups of points belonging to different sea areas. It is also interesting that the new data for the Black Sea obtained via GIOP are in good agreement with those previously described in $[10,11]$. Thus, if the GIOP application results for the processsing of satellite surveys of the Black Sea and the Pacific Ocean are considered together, the independent variability manifestations of the light absorption components $a_{\mathrm{ph}}(\lambda)$ and $a_{\mathrm{dg}}(\lambda)$ can be clearly seen. This circumstance plays an important role in the study of the optical properties of seawater, the determination of bioproductivity, etc. If, on the other hand, we confine ourselves only to those data shown in Fig. 6 for the Black Sea, it can be assumed that there is a more or less stable 
correlation dependence between $a_{\mathrm{ph}}(\lambda)$ and $a_{\mathrm{dg}}(\lambda)$, but for its reliable justification a more detailed study, going beyond the scope of this paper, is required.

\section{Conclusions}

The analysis performed allows better understanding of the principal possibilities of quantitative interpretation of satellite data in terms of spectral dependences of optically active components of sea water. Although the MODIS and SeaWiFS data often contain serious distortions in the Black Sea observations, careful selection of the most reliable data provides useful information on the optical properties of the upper layer of water.

In the examples considered, the spectral dependences of the sea surface reflectances are reproduced with good accuracy by the GIOP model used in the operational processing of accumulated satellite measurements. The results of the comparison of the effect of yellow substance dissolved in water and phytoplankton on the total absorption of light in different parts of the spectrum reflect the regional features of the Black Sea and the equatorial Pacific Ocean. In the Black Sea, an important contribution is made by $a_{\mathrm{dg}}$ component, whereas $a_{\mathrm{dg}}$ plays a weak role in the equatorial Pacific Ocean.

\section{REFERENCES}

1. O'Reilly, J.E., Maritorena, S., Mitchell, B.G., Siegel, D.A., Carder, K.L., Garver, S.A., Kahru, M. and McClain, C., 1998. Ocean Color Chlorophyll Algorithms for SeaWiFS. Journal of Geophysical Research, [e-journal] (103), pp. 24937-24953. doi:10.1029/98JC02160

2. Suetin, V.S., Suslin, V.V., Korolev, S.N. and Kucheryavyi, A.A., 2002. Analysis of the Variability of the Optical Properties of Water in the Black Sea in Summer 1998 according to the Data of a SeaWiFS Satellite Instrument. Physical Oceanography, [e-journal] 12(6), pp. 331-340. doi:10.1023/A:1021729229168

3. Kopelevich, O.V., Burenkov, V.I. and Sheberstov, S.V., 2006. Razrabotka I Ispol'zovanie Regional'nykh Algoritmov dlya Rascheta Bioopticheskikh Kharakteristik Morey Rossii po Dannym Sputnikovykh Skanerov Tsveta [The Development and Using of the Regional Algorithms for the Calculation of the Bio-Optical Characteristics of Russian Seas from Ocean Color Satellite Data]. Sovremennye Problemy Distantsionnogo Zondirovaniya Zemli iz Kosmosa [Current Problems in Remote Sensing of the Earth from Space], 3(2), pp. 99-105 (in Russian).

4. Kopelevich, O.V., Vazyulya, S.V., Saling, I.V., Sheberstov, S.V. and Burenkov, V.I., 2015. Elektronnyy Atlas "Bioopticheskie Kharakteristiki Morey Rossii po Dannym Sputnikovykh Skanerov Tsveta 1998-2014 gg." [Electronic atlas "Biooptical Characteristics of the Russian Seas from Satellite Ocean Color Data of 1998-2014"]. Sovremennye Problemy Distantsionnogo Dondirovaniya Zemli iz Kosmosa, 12(6), pp. 99-110.

5. Cota, G.F., Wang, J. and Comiso, J.C., 2004. Transformation of Global Satellite Chlorophyll Retrievals with a Regionally Tuned Algorithm. Remote Sensing of Environment, [e-journal] 90(3), pp. 373-377. doi:10.1016/j.rse.2004.01.005

6. Tassan, S., 1994. Local Algorithms Using SeaWiFS Data for the Retrieval of Phytoplankton, Pigments, Suspended Sediment, and Yellow Substance in Coastal Waters. Applied Optics, [ejournal] 33(12), pp. 2369-2378. doi:10.1364/AO.33.002369

7. Burenkov, V.I., Kopelevich, O.V., Sheberstov, S.V., Artemyev, V.A., Grigoriev, A.V., Ershova, S.V., Taskaev, V.R. and Khrapko, A.N. Opticheskiy Monitoring Biologicheskogo i Ekologi-cheskogo Sostoyaniya Chernogo Morya [Optical Monitoring of Biological and Ecological State of the Black Sea]. In: A. G. Zatsepin, M. F. Flint eds., 2002. Kompleksnye Issledovaniya Severo-Vostochnoy Chasti Chernogo Morya [Multidisciplinary Investigations of the Northeast Part of the Black Sea]. Moscow: Nauka, pp. 417-436 (in Russian). 
8. Lee, Z.-P. ed., 2006. Remote Sensing of Inherent Optical Properties: Fundamentals, Tests of Algorithms and Applications. Reports of the International Ocean-Colour Coordinating Group, No. 5. Canada, Dartmouth: IOCCG, 126 p. Available at: http://ioccg.org/reports/report5.pdf [Accessed: 01 November 2017].

9. Werdell, P.J., Franz, B.A., Bailey, S.W., Feldman, G.C., Boss, E., Brando, V.E., Dowell, M., Hirata, T., Lavender, S.J. and Zhongping L. [et al.], 2013. Generalized Ocean Color Inversion Model for Retrieving Marine Inherent Optical Properties. Applied Optics, [e-journal] 52(10), pp. 2019-2037. https://doi.org/10.1364/AO.52.002019

10. Suetin, V.S., Korolev, S.N. and Kucheryavy, A.A., 2014. Ispol'zovanie Sputnikovykh Nablyudeniy dlya Opredeleniya Spektral'nykh Zavisimostey Opticheskikh Kharakteristik Vod Chernogo Morya [Application of Satellite Observations for Determining Spectral Dependences of the Black Sea Waters Optical Characteristics]. Morskoy Gidrofizicheskiy Zhurnal, (3), pp. 77-86. Available at: http://dspace.nbuv.gov.ua/handle/123456789/105132 [Accessed: 01 November 2017] (in Russian).

11. Suetin, V.S., Korolev, S.N. and Kucheryaviy, A.A., 2016. Sun Glint Manifestation at Evaluating the Black Sea Water Optical Parameters Using Satellite Measurements. Physical Oceanography, [e-journal] (3), pp. 47-56. doi:10.22449/1573-160X-2016-3-47-56

12. Suetin, V.S., Korolev, S.N., Suslin, V.V. and Kucheryavyi, A.A., 2011. Comparative Analysis of the Methods Used for the Determination of the Optical Parameters of Waters in the Black Sea According to the Data of Satellite Measurements. Physical Oceanography [e-journal], 21(2), pp. 106-114. doi:10.1007/s11110-011-9108-4

13. Suetin, V.S., Tolkachenko, G.A., Korolev, S.N. and Kucheryavy, A.A., 2013. Opticheskie Svoystva Aerozoley i Atmosfernaya Korrektsiya Sputnikovykh Nablyudeniy Chernogo Morya [Optical Features of Aerosols and Atmospheric Correction of Satellite Observations of the Black Sea]. Morskoy Gidrofizicheskiy Zhurnal, (1), pp. 34-44 (in Russian).

14. Sydor, M., Gould, R.W., Arnone, R.A., Haltrin, V.I. and Goode, W., 2004. Uniqueness in Remote Sensing of the Inherent Optical Properties of Ocean Water. Applied Optics, [ejournal] 43(10), pp. 2156-2162. doi:10.1364/AO.43.002156

15. Churilova, T.Ya., Suslin, V.V. and Sosik, H.M., 2002. A Spectral Model of Underwater Irradiance in the Black Sea. Physical Oceanography, [e-journal] 19(6), pp. 366-378. doi:10.1007/s11110-010-9060-8

16. Burenkov, V.I., Kopelevich, O.V., Sheberstov, S.V., Ershova, S.V. and Evdoshenko, M.A., 1999. Bio-Optical Characteristics of the Aegean Sea Retrieved from Satellite Ocean Color Data. In: P. Malanotte-Rizzoli, V.N. Eremeev eds., 1999. The Eastern Mediterranean as a Laboratory Basin for the Assessment of Contrasting Ecosystems. NATO Science Series (Series 2: Environmental Security, vol. 51). Dordrecht: Springer, pp. 313-326. doi:10.1007/978-94-011-4796-5

17. Organelli, E., Claustre, H., Bricaud, A., Barbieux, M., Uitz, J., D’Ortenzio, F. and Dall'Olmo, G., 2017. Bio-Optical Anomalies in the World's Oceans: An Investigation on the Diffuse Attenuation Coefficients for Downward Irradiance Derived from Biogeochemical Argo Float Measurements. Journal of Geophysical Research: Oceans, [e-journal] 122(5), pp. 3543-3564. doi:10.1002/2016JC012629

18. Churilova, T.Ya., Suslin, V.V. and Rylkova O.A., 2008. Parametrizatsiya Pogloshcheniya Sveta Osnovnymi Opticheski Aktivnymi Komponentami v Chernom More [Parametrization of Light Absorption by All Main Optically Active Components in the Black Sea]. In: MHI, 2008. Ekologicheskaya Bezopasnost' Pribrezhnykh i Shel'fovykh Zon i Kompleksnoe Ispol'zovanie Resursov Shel'fa [Ecological Safety of Coastal and Shelf Zones and Comprehensive Use of Shelf Resources]. Sevastopol: ECOSI-Gidrofizika. Iss. 16, pp. 190-201 (in Russian).

19. Kopelevich, O.V., Burenkov, V.I., Ershova, S.V., Sheberstov, S.V. and Evdoshenko, M.A., 2004. Application of SeaWiFS Data for Studying Variability of Bio-Optical Characteristics in the Barents, Black and Caspian Seas. Deep Sea Research Part II: Topical Studies in Oceanography, [e-journal] 51(10-11), pp. 1063-1091. doi:10.1016/j.dsr2.2003.10.009 
20. Gregg, W.W. and Casey, N.W., 2004. Global and Regional Evaluation of the SeaWiFS Chlorophyll Data Set. Remote Sensing of Environment, [e-journal] 93(4), pp. 463-479. doi:10.1016/j.rse.2003.12.012

21. Chavez, F.P., Strutton, P.G., Friederich, G.E., Feely, R.A., Feldman, G.C., Foley, D.G. and McPhaden, M.J., 1999. Biological and Chemical Response of the Equatorial Pacific Ocean to the 1997-98 El Niño. Science, [e-journal] 286(5447), pp. 2126-2131. doi:10.1126/science.286.5447.2126

22. Platt, T., Hoepffner, N., Stuart, V. and Brown, C. eds., 2008. Why Ocean Colour? The Societal Benefits of Ocean-Colour Technology. Reports and Monographs of the International OceanColour Coordinating Group, No. 7. Canada, Dartmouth: IOCCG, 141 p. Available at: http://ioccg.org/wp-content/uploads/2016/02/report7.pdf [Accessed: 01 November 2017].

About authors:

Vadim S. Suetin - Leading Research Associate, Department of Dynamics of the Oceanic Processes, FSBSI MHI (2 Kapitanskaya St., Sevastopol, Russian Federation, 299011), Ph.D. (Phys.Math.), SPIN-code: 5796-6883, ORCID ID: 0000-0001-7278-667X, ResearcherID: M-6879-2018, v.suetin@mhi-ras.ru

Sergey N. Korolev - Junior Research Associate, Department of Dynamics of the Oceanic Processes, FSBSI MHI (2 Kapitanskaya St., Sevastopol, Russian Federation, 299011), SPIN-code: 9420-9479, ORCID ID: 0000-0001-5704-8863, ResearcherID: M-6584-2018, s.korolev@mhiras.ru

Contribution of the co-authors:

Sergey N. Korolev - computer implementation of algorithms, development and debugging of the computer program for solving the problem, works on PC, discussion of the results, construction of the tables, graphs and diagrams; the text revision.

Vadim S. Suetin - scientific supervision, the problem setting out and formulation, development of mathematical model, the methodology development, qualitative analysis of the results and their interpretation, making conclusions, reference selection and analysis, preparation of the text of the article, writing the summary.

All the authors have read and approved the final manuscript.

The authors declare that they have no conflict of interest. 